\title{
A Comparative Study on Chinese and Japanese Animal Proverbs: Taking Dog, Fish, Cattle Proverbs as Example
}

\author{
Zixi Wei, Guifang Zhang, Rui Zhao* \\ Southwest Minzu University, Chengdu, China \\ Email: *ZXW20202021@163.com
}

How to cite this paper: Wei, Z.X., Zhang, G.F. and Zhao, R. (2021) A Comparative Study on Chinese and Japanese Animal Proverbs: Taking Dog, Fish, Cattle Proverbs as Example. Open Access Library Journal, 8: e7768.

https://doi.org/10.4236/oalib.1107768

Received: July 16, 2021

Accepted: August 1, 2021

Published: August 4, 2021

Copyright $\odot 2021$ by author(s) and Open Access Library Inc.

This work is licensed under the Creative Commons Attribution International License (CC BY 4.0).

http://creativecommons.org/licenses/by/4.0/

\begin{abstract}
Proverbs are not only the crystallization of human wisdom, but also the treasure of human art and culture. Our ancestors have lived with animals for generations, endowed them with rich and complex meanings, and the language phenomenon of using animals as metaphors is common. China and Japan are separated by a strip of water and have had many cultural exchanges in history. Therefore, the cultural similarities and differences that the two countries give to animals are also worth exploring. This paper tries to make a comparative analysis of the proverbs related to "dog, fish and cow", and make some research on the similarities and differences and cultural background between China and Japan in this aspect. Hope to help Japanese learners to better grasp the cultural differences between the two countries.
\end{abstract}

\section{Subject Areas}

Linguistics

\section{Keywords}

Animal Proverbs, Chinese Proverbs, Japanese Proverb, Chinese-Japanese Proverbs Comparison

\section{1. 引言}

培根有言: “谤语是一个民族天才、机智和精神的体现。” [1]日语里写 作 “諺” 即 “ことわざ。昔から言い伝えられた、教訓や風刺を含んだ簡潔 な文句”。中文意思: 从远古流传下来, 具有讽刺, 教训意味的简洁短语。 浐语是一个国家和民族生活哲理、丰富文化内涵的概括与总结。我们都知道 ${ }^{\star}$ Corresponding author. 
日本四面环海, 是个靠海为生的海洋民族, 其浐语就多涉及鱼、虾、蟹等。 而中国作为农业大国, 身为农耕民族则多涉及牛、羊、骆驼等动物。由于两 国的文化差异, 所以往往会给同一动物打上不同色彩的文化烙印。那么, 在 动物浐语方面中、日两国又有哪些文化异同呢?

\section{2. 与狗有关的谚语}

在中国古时候, 狗是富人与达官贵族看家护院的利器。“狗” 摇头摆尾 的形象, 凶恶的嘴脸, 尖利的牙齿, 刺耳的叫声, 以及狗对乞正和穷人的攻 击等等, 使得狗的形象严重受损。这样, 就很容易让人把狗与阿舆谄媚的小 人和倚仗权势对穷人作威作福的无耻之辈联系起来。因此在我国以 “狗” 来 喻人喻事多少就带有些贬义, 其形象也就不言而喻。例如:

【狗肚里没人话】 [2]

喻指坏人一肚子坏水, 绝对干不出好事来。

【狗改不了吃屎】[2]

说明坏人改不了做坏事的本性。有时也说, 狗忘不掉吃屎或狗改不了吃 屎, 狼改不了吃人。

【狗肉滚三滚, 神仙站不稳】[2]

意思是说, 吃喝等物质诱惑力大, 人们难以抵御, 容易受腐蚀拉拢, 被 拉下水。

【狗眼看人低】 $[2]$

比喻小人得势, 高傲自大看不起人。

在日本狗也被写成 “犬”, 日语词典《广辞苑》 [3]中的解释是: 狗嗅觉 和听觉很灵敏, 是作为狩猎用(猎犬)、军用(警犬)、劳役用(雪楿犬)、玩赏用(宠 物狗)而被广泛饲养的家畜。所以日本人认为狗的用途很广, 同时它也是忠诚、 沉毅和威严的象征。从电影《忠犬八公的故事》 ${ }^{1}$ 中也可以看出他们对狗的喜 爱, 所以在日语浐语中大多是正义的形象。例如:

【狗奴国】魏志倭人伝にみえる弥生時代の倭わの強国。邪馬台国の南 にあって男王が支配し、女王をいただく邪馬台国と対立していた[3]。

中文意思：根据《魏志倭人传》中所说, 在日本弥生时代, 与 “邪马台 国” 南边对立被男王支配的国家叫 “狗奴国”。因此古代日本也有 “狗奴国” 之称。“倭” 是古代中国对日本列岛以及其近邻的通称, 居民称之为倭人, 而其国家称之为倭国，但并无侮辱的成分。

【犬は三日飼えば三年恩を忘れぬ。】

中文意思: 就算养狗三日, 它三年也不会忘掉主人对它的恩惠。字面意 思就是连狗都不忘三年的恩, 所以人就更加不能忘恩负义了。

【犬が西向きゃ尾は東】 [4]

中文意思: 狗朝西边看, 它的尾巴自然就会摆向东边。强调是理所当然 的话。

【犬の穂掛】 [3]

影片《忠犬八公的故事》改编自 1925 年发生在日本的真实故事, 由莱塞 - 霍尔斯道姆执导。 该片讲述了一段人和狗之间感人肺腑的故事。 
中文意思：狗日挂穗。通常古代日本在第一天收割麦穗的日子正值 “戌 日”, “戌” 在十二生肖里面对应狗, 所以这一天也叫狗穗日, 人们会用麦 穗向神灵祭祀, 以表达丰收的感激之情。

因此, 通过以上例子可以看出两国在狗的形象上就产生了差异, 在中国 是贬义, 在日本却是售义。

\section{3. 与鱼有关的谚语}

在中国, 古人认为锦鲤能给人们带来好运, 所以被当作是吉祥的象征。 锦鲤作为一种观赏鱼早期只供达官贵族欣赏, 后来, 才在民间流传。人们喜 欢鱼, 素有 “无鱼不欢” 之句。中国自古以来也有 “鲤鱼跃龙门”一说, 比 喻人飞黄腾达, 所以鱼在我国是好的寓意。例如:

【鱼不怕水深, 虎不怕林深】

喻指有远大志向和有本领的人不怕到艰苦的地方去工作。

【鱼怕离水, 草怕见霜】 [5]

喻指人或事物都有致命的弱点。

【鱼有鱼路, 虾有虾路】[2]

喻指不同的人, 会有不同的办法。

【鱼与熊掌不可兼得】

该浐语出自孟子《鱼我所欲也》, 用鱼来比喻珍贵的事物。即: 美好的 东西不能两全, 人要学会取舍。

同样, 在日本鱼也象征着 “吉祥”。到了每年的五月五日, 日本男孩节(鲤 のぼりにいのぼり), 家家户户就会插上鲤鱼旗, 日本人也常常用鱼来装饰家 居和服装。把鱼作为名字的现象也屡见不鲜, 比如: 明石家さんま。中文名: 明石家秋刀鱼(其中さんま和 “秋刀鱼” 同音)同时, 鲤鱼也被认为是力量和 勇气的象征, 表达了父母望子成龙, 对孩子美好祈盼的愿望。所以鱼在日本 也是好的象征。例如:

【魚の水を得たるが如し】[4]

中文意思：如鱼得水。

【鱼心あれば水心有り】[3]

中文意思: 鱼有心来, 水也有心。比喻人心都是肉长的, 别人对自己好 的话, 也同样对对方报以好意。

【腐っても鯛】[6]

中文意思: 即使腐烂了, 也是好吃的鲖鱼。指本来优秀东西, 即使葄落 了也会有相应的价值。即: 瘦死的骆驼比马大。日本人作为海洋民族, 宁可 一日无肉, 不可一日无鱼。他们认为鱼不属于肉, 也对各种鱼了如指掌。所 以, 深知鲖鱼的美味。

因此, 通过对比可知, 在 “鱼” 的形象上中日两国都为亭义, 鱼都寓意 “吉祥如意”。

\section{4. 和牛有关的谚语}

在我国, 素有 “俯首甘为孺子牛” 的名句, 所以 “牛” 也象征着勤奋和 
脚踏实地。但有时候人们也常用 “蚌牛” 来指代愚蚌的人。嘲讽不识丁者为 “青瞑牛” (即: 瞎眼牛)。报恩于人叫 “做牛做马”也多指劳累, 辛苦之事。 所以牛在我国大多是贬义, 笨拙的形象。例如:

\section{【对牛弹琴】}

汉・牟融《理惑论》: “公明仪为牛弹清角之操, 伏食如枚。非牛不闻, 不合其耳矣。”比喻说话不看对象。

【牛头不对马嘴】

比喻答非所问, 做事不合逻辑。

【牛角上抹油, 又尖又滑】[5]

尖, 是 “奸” 的同音借用。形容人奸计多变, 与老奸巨猾同义。

【牛套马, 累死俩】[2]

比喻双方互相牵制, 不但事情不能配合着做好, 而且双方都会被拖垮。

日本关于牛的解释是: 牛分为肉牛、奶牛、耕牛, 各有很多品种, 其肉、 乳可以食用, 皮、骨、角等也可供多种用途[3]。据说牛在日本传入之初, 因 为数量稀少, 所以被当成是珍稀的家畜。加之当时农业尚未发达, 所以一开 始并没有作为劳动力用以耕作。而是作为地位和权利的象征, 供贵族、武士 作为代步。因此, 牛在日本是慜厚老实的形象, 多为襄义。例如:

【牛耳を執る】[3]

中文意思：执牛耳者。比喻掌握大权的人, 或是重要人物。

【商いは牛の涎】 [3]

中文意思: 做生意要像牛的口水那样。比喻做事应有耐心, 像牛的口水 那样, 细水流长。

【牛も千里、馬も千里】[6]

中文意思: 马走了千里, 牛也走了千里。比喻殊途同归。牛虽然走的慢, 马虽然跑得快, 但牛和马都一样走了千里。比喻不管过程怎样, 其结果是一 样的。

通过对比, 在 “牛” 的形象上, 中日两国看法也不太一样, 中国认为牛 实属 “笨拙” 贬义而日本却认为是 “踏实” 多为襄义。

\section{5. 中日两国在动物浐语方面文化存在差异的原因}

1) 地理环境不同: 中日两国虽然是近邻, 但在地理环境方面却存在很大 的差异。日本四面环海, 是海洋民族, 所以基本上是靠山吃山, 靠海吃海。 但由于受岛国狭小的地理因素的限制, 又使得日本人在语言行为上更小心谨 慎, 毕恭毕敬更加注重细节和礼节[7], 所以有关动物浐语方面多为襄义, 生 怕得罪人。而土地和自然资源的有限在一定程度也限制了日本的发展, 这一 因素也让日本人更加重视作为耕地的牛和作为狩猎看家的狗, 因此浐语里对 其大加赞赏。

中国自古以来疆域辽阔, 经纬跨度大, 由于地大物博地理因素的影响, 中国文化的包容性和差异性也在于此。所以对于动物浐语, 与日本看法也有 所不同, 有襄有贬。而这一切都与两国不同的地理环境有着密切的关系。

2) 传统文化不同: 中日两国自古交往密切, 有许多相似之处, 所以对于 
动物所蕴含的文化色彩认知大致相同。如鱼都是吉祥的象征。但在其他文化 方面却又异于我国传统文化。

从整体上来说, 中国文化属于辩白文化而日本属于道歉文化。在传统文 化里, 日本人所使用 “对不起” 的频率远远高于说 “谢谢” 的频率, 这就是 “道歉文化” 而致。因此，与其国民性相当䇾厚老实、任劳任怨的 “牛”， 也受到了器重。而我们都知道中国人 “好面子”, 尤其是在犯了错误之后, 通常情况下首先喜欢去 “解释” 原因。这就是 “辩白文化” , 对于老实㮩厚 的牛, 中国人骂人的时候喜欢说: “敗得像头牛”, 被人牵着 “牛鼻子” 走, 真是毫无主见。由此看来, 传统文化的不同可能也是两国对于动物有关浐语 方面的一个重要因素。

3）价值观念不同: 中日两国的价值观念有所不同, 中国人爱憎分明, 而 日本人态度模糊暧昧。比如: 我们从小看电视、电影就喜欢评价, 哪个人是 好人, 哪个人是坏人, 太在意好与坏, 爱与憎了。其中浐语对狗的憎就是显 而易见的。“狗急跳墙”、“挂羊头卖狗肉” 等。而日语本身就很暖昧, 总 是给人模糊的态度。比如【犬一代に狸一匹】 [6]中文意思：狗一生最多也只 能捕到一次狐狸。那这算好事还是坏事也就很模糊了。这也间接说明了价值 观念的不同可能是两国在动物浐语方面文化存在差异的一个重要因素。

4) 民族情趣不同: 我们知道日本是一个喜欢旅游的民族, 从古代他们就 前仆后继派出遣隋使、遣唐使不远万里来中国学习, 到明治维新去西方学习 先进文化, 直至当今, 他们周游世界的脚步也从未停止, 对旅行出门也情有 独钟。如浐语【犬も歩けば棒に当たる】中文意思: 要多学学狗在外边多走 走没准会碰上意想不到的幸运。比喻鼓励年轻人要多出去闯荡, 不要老是呆 在家做白日梦。

相比之下, 中国人因为是农耕文化, 所以潜意识里就是一个喜欢安定的 民族。因此对在外闯荡漂泊的生活则是感到不安的。所以对喜欢到处转悠狗 评价多为贬义, 如浐语: “狗瞎转悠被棍打”、“好狗不挡道” 等。这也说 明了民族情趣的不同是两国动物浐语文化差异的一个重要原因。

5) 思维方式不同: 语言与思维关系极为密切, 如果说语言是文化的镜子, 那么思维方式就是凝结着人类智慧与创造的一个折射。日本人的思维方式的 一个重要特点整体性思维, 喜欢以集体为单位抉择。如浐语: 【尻馬に乗る】 [3]中文意思: 指拍马屁, 跟在别人后面, 附和雷同。说的就是喜欢集体跟风 这一现象。中国人则是以个体性思维居多, 喜欢以个体为单位。所以浐语 “狗 拿耗子多管闲事” 表现了我们事不关已高高挂起的个体性思维方式。因此思 维方式的不同也是导致两国对于动物形象襄贬不一的重要影响因素。

\section{6. 结语}

本文就 “狗, 鱼, 牛” 中日两国的浐语作了一些简单对比。可知, 狗在 我国是 “无耻、谄媚” 的形象, 而在日本却是 “忠诚、威严” 的形象; 牛在 我国是 “慜厚、笨拙” 的形象, 而在日本却是 “勤劳, 踏实” 的形象; 鱼在 两国都是 “吉祥” 的形象。这些都说明了中、日两国在动物浐语方面文化确 实是存在差异的。 
那么差异是如何形成的呢? 语言是非常复杂的系统, 它受地理、文化等 多种要素影响，尤其是民众熟知的浐语，在语言漫长的发展历史中，无不受 到社会、历史、文化、民众心理、价值观念等各种影响。所以，中日两国关 于动物谚语认知差异的产生可能是由以下几个因素引起：地理环境差异；传 统文化差异; 价值观念差异; 民族情趣差异; 思维方式差异等。因此, 日常 在学习有关日本文化或是与日本人交谈这些跨文化问题时一定要格外地注意 这些动物谤语的用法。

\section{Conflicts of Interest}

The authors declare no conflicts of interest.

\section{References}

[1] 李新艳. 法汉浐语对比研究[D]: [硕士学位论文]. 厦门: 厦门大学, 2007.

[2] 张毅. 常用浐语词典 $[\mathrm{M}]$. 上海: 上海辞书出版社, 1987.

[3] 新村出. 広辞苑無料検索 [Z/OL]. https://sakura-paris.org/dict/

[4] 刘震宇, 刘剑. 详解日语惯用语词典 [M]. 上海: 上海译文出版社, 2008.

[5] 邱崇丙. 俗语五千条[专著] [M]. 西安：陕西人民出版社, 1983.

[6]叶琳. 常用日语惯用型 $[M]$. 合肥: 安徽科学技术出版社, 2007.

[7] 杨董玲. 日本地理环境对日本文化的影响 [J]. 文教资料, 2006(21): 89-90.

\section{Appendix (Abstract and Keywords in Chinese) 中日动物谤语的比较研究——以 “狗, 鱼, 牛” 为例}

摘要：浐语不仅是人类智慧的结晶, 也是人类艺术文化的珍宝。我们的 祖先世世代代就与动物共处, 给动物赋予了丰富而复杂的意义, 并且以动物 设喻的语言现象也屡见不鲜。中日两国是一衣带水的国家, 在历史上也有很 多文化交流和往来。所以，两国给动物赋予的文化异同也值得我们深究。本 文试着就 “狗、鱼、牛” 有关的浐语进行比较分析，对中日两国在该方面的 异同与文化背景做出一些探究。希望对日语学习者起到一定帮助, 进而更好 地把握两国间文化的差异。

关键词：动物浐语，中文谚语，日语浐语，中日浐语比较 